JOURNAL OF

SYNCHROTRON

RADIATION

ISSN 1600-5775

Received 8 August 2016

Accepted 12 January 2017

Edited by A. Momose, Tohoku University, Japan

Keywords: cell design; molten-salt reduction; spent fuel reprocessing; energy-dispersive $\mathrm{X}$-ray diffraction.

Supporting information: this article has supporting information at journals.iucr.org/s

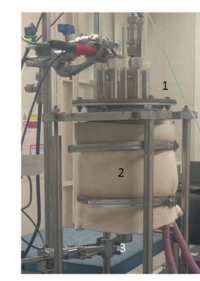

OPEN $\odot$ ACCESS

\section{A novel molten-salt electrochemical cell for investigating the reduction of uranium dioxide to uranium metal by lithium using in situ synchrotron radiation}

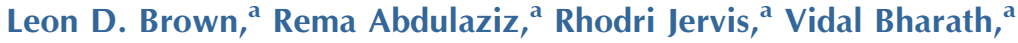 \\ Thomas J. Mason, ${ }^{a}$ Robert C. Atwood, ${ }^{\mathrm{b}}$ Christina Reinhard, ${ }^{\mathrm{b}}$ Leigh D. Connor, ${ }^{\mathrm{b}}$ \\ Douglas Inman, ${ }^{a}$ Daniel J. L. Brett ${ }^{\mathrm{a}}$ and Paul R. Shearing ${ }^{\mathrm{a} *}$
}

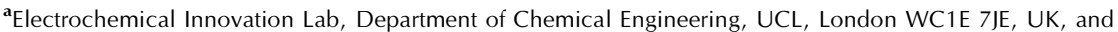
${ }^{\mathbf{b}}$ Diamond Light Source, Harwell Science and Innovation Campus, Didcot, Oxfordshire OX11 ODE, UK.

*Correspondence e-mail: p.shearing@ucl.ac.uk
}

A novel electrochemical cell has been designed and built to allow for in situ energy-dispersive $\mathrm{X}$-ray diffraction measurements to be made during reduction of $\mathrm{UO}_{2}$ to $\mathrm{U}$ metal in $\mathrm{LiCl}-\mathrm{KCl}$ at $500^{\circ} \mathrm{C}$. The electrochemical cell contains a recessed well at the bottom of the cell into which the working electrode sits, reducing the beam path for the X-rays through the molten-salt and maximizing the signal-to-noise ratio from the sample. Lithium metal was electrodeposited onto the $\mathrm{UO}_{2}$ working electrode by exposing the working electrode to more negative potentials than the $\mathrm{Li}$ deposition potential of the $\mathrm{LiCl}-\mathrm{KCl}$ eutectic electrolyte. The Li metal acts as a reducing agent for the chemical reduction of $\mathrm{UO}_{2}$ to $\mathrm{U}$, which appears to proceed to completion. All phases were fitted using Le Bail refinement. The cell is expected to be widely applicable to many studies involving molten-salt systems.

\section{Introduction}

The electrochemical reduction of metal oxides to their metal phase using molten-salt media has gained significant interest since the FFC Cambridge process was realised (Chen et al., 2000). Many studies have been performed in order to understand the electro-reduction pathway (Alexander et al., 2006; Schwandt \& Fray, 2005). However, due to the high temperature at which molten-salt electrolytes typically operate, the ex situ analysis of electrodes may be problematic and affected, for example, by structural changes associated with large changes in temperature and the removal of water-soluble species during cleaning of electrodes (Bhagat et al., 2010).

Metal-chloride molten salts may be deployed as electrolytes due to their high ionic conductivities and, furthermore, the high temperatures at which these systems operate $(>523 \mathrm{~K})$ also afford rapid electrode kinetics. During electro-reduction in molten-salt environments, the metal oxide to be reduced is made into the working electrode and a graphite (or metallic) rod is made into the counter electrode. Upon polarizing the working electrode to sufficiently negative potentials, the reduction of these metal oxides may occur, liberating $\mathrm{O}^{2-}$ ions which are then transported through the electrolyte to the anode where it is oxidized to $\mathrm{CO}_{2}, \mathrm{CO}$ or $\mathrm{O}_{2}$ (depending on the material of the anode). In typical laboratory setups, this configuration is usually contained within a glassy carbon, ceramic or glass crucible. 
Spent nuclear fuel reprocessing using molten salts was first demonstrated in the 1970s using the pyro-processing technique for the processing of integral fast reactor fuels using cadmium chloride to reduce metallic spent fuel in lithium chloride-potassium chloride eutectic (LKE), followed by electro-refining (Pierce et al., 1993; Laidler, 1993; Laidler et al., 1997). A similar pyrochemical technique has been investigated in $\mathrm{Li}_{2} \mathrm{O}$-doped $\mathrm{LiCl}$, which chemically reduces spent fuel oxides by electrochemically plating $\mathrm{Li}$ onto the spent fuel electrode (Hur et al., 2003; Seo et al., 2006; Jeong et al., 2010; Kurata et al., 2004). More recently, a pyro-electrochemical technique has been investigated which aims to electrochemically reduce spent fuel oxides, followed by selective electrodeposition in LKE (Brown et al., 2013, 2015; Hu et al., 2014). The focus of this paper is to demonstrate the experimental design and methodology developed to study the metal/ molten-salt system using energy-dispersive X-ray diffraction. Here, our studies focus on the chemical reduction of $\mathrm{UO}_{2}$ by plating $\mathrm{Li}$ onto the working electrode in molten $\mathrm{LKE}$ at $450^{\circ} \mathrm{C}$ which is characterized in situ using synchrotron radiation.

In situ neutron diffraction and X-ray diffraction are valuable tools for identifying crystalline phases in the actual environment in which processes occur. For example, many ex situ studies observed the formation of $\mathrm{Ti}_{3} \mathrm{O}_{5}$ as an intermediate phase during the electrochemical reduction of $\mathrm{TiO}_{2}$ to Ti in the FFC Cambridge process (Dring et al., 2005; Schwandt \& Fray, 2005; Alexander et al., 2006). However, during in situ $\mathrm{X}$-ray diffraction, this phase was not observed (Bhagat et al., 2010). Furthermore, in a recent in situ study the electrochemical reduction of $\mathrm{UO}_{2}$ to $\mathrm{U}$ in molten LKE was shown to occur in a single, four-electron transfer, process and occurred at a potential marginally more positive than the potential for Li deposition from the electrolyte (Brown et al., 2013, 2015).

In this work, the design processes and considerations for the novel electrochemical cell used by Brown et al. (2015) are described in order to combine electrochemical measurements with in situ energy-dispersive X-ray diffraction. The authors also present a second electrochemical reduction mechanism: the chemical reduction of $\mathrm{UO}_{2}$ to $\mathrm{U}$ from electroplated $\mathrm{Li}$ metal from the electrolyte. The cell design presented is expected to fulfil a broader application for operando experimentation of molten-salt systems.

\section{Materials and methods}

A novel electrochemical cell, containing a 'well' at the bottom (where the working electrode is located), was manufactured from aluminium due to its low attenuation of X-rays. Incorporation of the well limited the X-ray beam path length through the sample environment, thus reducing attenuation by the structural components of the cell, and the molten-salt media. This would increase the signal-to-noise ratio of the diffraction pattern and simplify the sample alignment. The balance-of-apparatus components (counter electrode, reference electrode and thermocouple) are contained within the main body of the vessel, as shown in Fig. 1. All wall thicknesses of the aluminium cell are $3 \mathrm{~mm}$.
The cell head was manufactured from 316 stainless steel, chosen due to its lower thermal conduction coefficient compared with aluminium. This then aids in desired cooling of the cell head. (In addition, stainless steel is easy to weld and reduces production time and cost, compared with aluminium.) The cell head also incorporated six hollow, open-ended, cylinders which were welded on top of the head. These were included to help ensure that the three electrodes, thermocouple and gas lines were held vertically (which helped to avoid possible short-circuiting of electrodes with the cell wall) and also acted as heat-transfer fins, again aiding cooling of the electrodes. The electrodes were held into the cell head cylinders via the use of high-temperature silicone rubber bungs. Electrical connections were made with a potentiostat by the use of crocodile clips crimped to the electrodes directly (see Fig. 1c). The cell head also incorporated Swagelok fittings with non-return valves to allow for gas flow through the cell and to
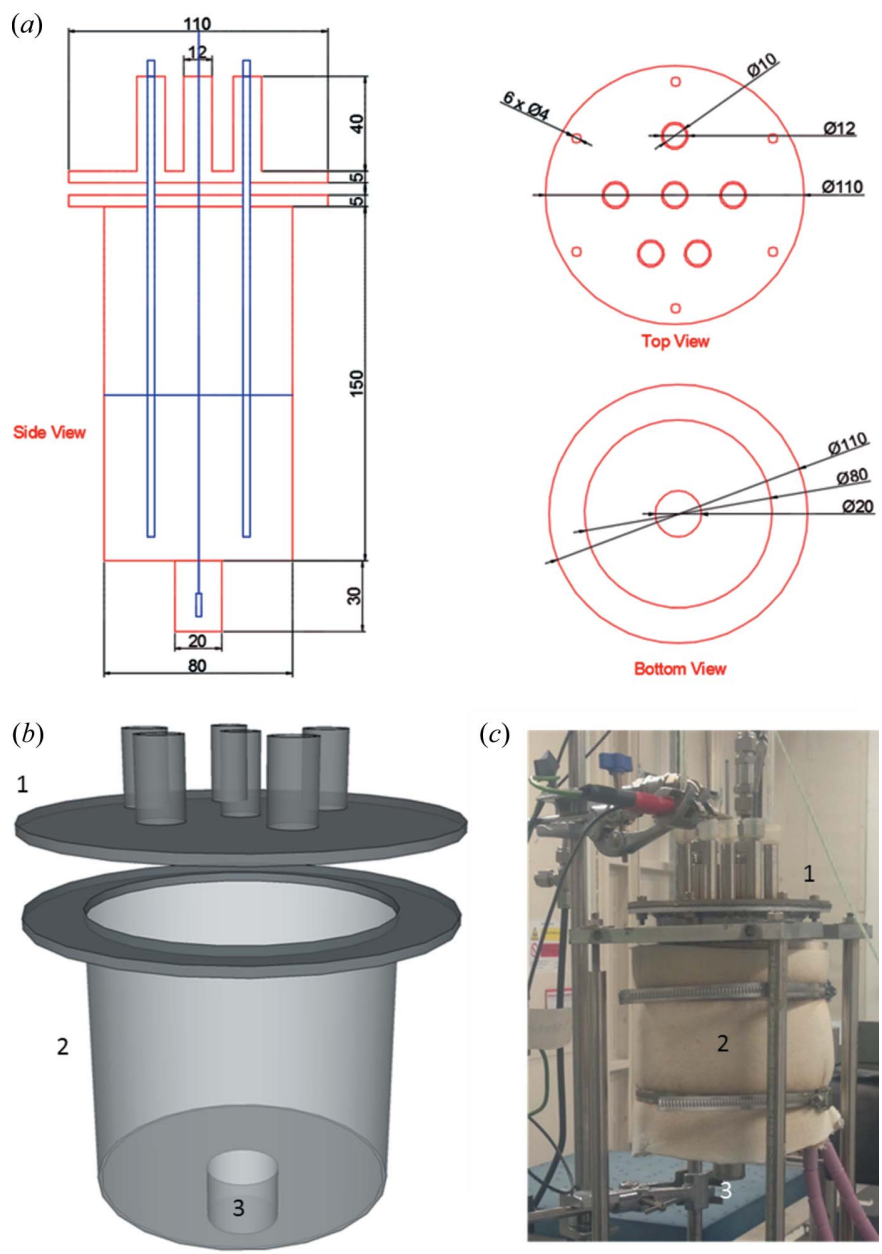

Figure 1

(a) CAD drawing of the electrochemical cell and electrochemical cell head used for experimentation. All dimensions stated are in $\mathrm{mm}$. (b) Three-dimensional schematic of the electrochemical cell and (c) photograph of the electrochemical cell setup on the beamline. 1: electrochemical cell head. 2: electrochemical cell. 3: 'well' in which the working electrode is positioned. Under operation, LKE fills approximately half of the vessel, as shown in blue in $(a)$. The positions of ancillary electrodes and thermocouple are also shown in blue. 
ensure no atmospheric gas would enter the cell during transportation from assembly in an argon-filled glove box.

A graphite gasket was also used to ensure a gas-tight fit between the stainless steel cell head and aluminium flange. The cell head was attached to the cell by the use of six M4 nuts and bolts located at angles of $60^{\circ}$ from the centre of the vessel. A computer-aided-design (CAD) drawing of the electrochemical cell may be seen in Fig. 1.

The electrochemical cell was assembled inside an argonfilled glove box which maintained an oxygen and moisture composition of $<0.1$ p.p.m. $300 \mathrm{~g}$ of dried LKE $(>99.9 \%$, Sigma-Aldrich) was loaded into the electrochemical cell, along with the electrodes and a glass-sheathed K-type thermocouple. The thermocouple was located $2 \mathrm{~mm}$ above the bottom of the electrochemical cell. Note that, due to local rules within the synchrotron buildings, the $\mathrm{UO}_{2}$ working electrode was unable to be loaded into the electrochemical cell inside the glove box and was required to be inserted into the cell on the beamline itself. The Suba-Seal design allowed for this to be achieved with a gas-tight seal.

A heating jacket was then secured to the electrochemical cell and connected to the PID-controlled power source. The heating jacket was a custom-built flexible ceramic pad heater (Artech Services, UK) powered by a three-phase transformer. The PID controller input was a single glass-sheathed K-type thermocouple which was immersed in the molten salt, which provided a constant, stable temperature reading at operating temperature. A layer of ceramic-based, flexible, furnace-grade insulation was also wrapped around the heating jacket. The insulation and heating jacket were fixed to the cell via a number of jubilee clips.

The cell was heated at a ramp rate of $10^{\circ} \mathrm{C} \mathrm{min}^{-1}$ from room temperature to a working temperature of $500^{\circ} \mathrm{C}$, as recorded by the thermocouple. Once the working temperature was achieved, pre-electrolysis (see $\$ 3$ for more details) was performed for $2 \mathrm{~h}$ to remove any electro-active contaminants from the molten salt. Once the electrochemical cell was secured onto the beamline sample stage, the gas line (research grade, $<0.5$ p.p.m. $\mathrm{H}_{2} \mathrm{O}$ and $\mathrm{O}_{2}$ ) was purged and connected to the electrochemical cell and the non-return valves were opened. The outlet gas was pumped through a series of gas traps to absorb any chlorine gas that may form during electrochemical measurements. The gas trap comprised a sequence of four Dreschel bottles: the first was empty to ensure no liquid flowed into the cell's gas outlet stream due to any back pressure; the second and third bottles contained $\mathrm{NaOH}$ solutions to absorb chlorine-containing vapours from the cell, and the last bottle was de-ionized water.

During experimentation, a metallic cavity electrode (MCE) filled with $\mathrm{UO}_{2}$ powder was employed as the working electrode. MCEs are fabricated by drilling a $0.5 \mathrm{~mm}$-diameter hole into a $0.5 \mathrm{~mm}$-thick metallic foil and are described elsewhere (Qiu et al., 2005; Rao et al., 2007). This study used a $2.5 \mathrm{~mm} \times$ $15 \mathrm{~mm} \times 0.5 \mathrm{~mm}(\mathrm{~W} \times \mathrm{L} \times \mathrm{D})$ Mo foil $(>99.9 \%$, Alfa Aesar $)$, into which five $0.5 \mathrm{~mm}$-diameter holes were drilled. Pure $\mathrm{UO}_{2}$ powder was prepared (Brown et al., 2015) and pressed into the five MCE holes. The MCE was attached to a $3 \mathrm{~mm}$-diameter
$250 \mathrm{~mm}$-long Mo rod using $0.2 \mathrm{~mm}$-diameter Mo wire (rod and wire both $>99 \%$, Alfa Aesar). This configuration was made the working electrode. A three-electrode setup was employed using a dense graphite rod (3.18 mm-diameter, Alfa Aesar) counter electrode and an all glass $\mathrm{Ag} / \mathrm{AgCl}$ reference electrode. All electrodes were held in place using silicone Suba-Seals (Sigma-Aldrich) which also allow for gas-tight sealing to be achieved.

The electrochemical cell here aims to achieve direct in situ characterization of electrochemical processes in molten-salt media, similar to that achieved by Styles et al. (2012) and Jackson et al. (2010). However, the furnace designs used in those studies used much more expensive materials, a result of the much higher temperatures required to heat $\mathrm{CaCl}_{2}$. In contrast, the LKE system operates at temperatures much lower than that of the melting point of aluminium which permits its use as a material of construction. In addition, the cell described in this work also permits the use of very small sample quantities in the form of MCE electrodes which allow for rapid completion of reactions and a reduction in any overpotential associated with metal oxide powder pellet electrode configurations.

Energy-dispersive X-ray diffraction (EDXD) measurements were performed on beamline I12 (JEEP) at Diamond Light Source in the UK (Drakopoulos et al., 2015). This diffraction technique differs from conventional, angulardispersive, X-ray diffraction as the $d$-spacing is derived by determination of the wavelength of the diffracted polychromatic photons [as opposed to being derived from the diffraction angle of monochromatic photons (Kämpfe et al., 2005)]. The diffraction angle may be kept constant by the use of two collimating slits and, as a direct result, a lozenge-shaped gauge volume is defined in space whereby only photons that are scattered from within this volume will be detected by the EDXD detector. The gauge volume is calculated to be $0.3 \mathrm{~mm}$ $\times 0.3 \mathrm{~mm} \times 7.075 \mathrm{~mm}$, using the method described by Rowels et al. (2011). This technique is particularly suited to the design of the electrochemical cell as the volume of the molten salt inside the well may be designed to be equal to the volume of the lozenge-shaped gauge volume. Placing the sample within this gauge volume has the advantage of being able to eliminate the signal from balance-of-apparatus components (the electrochemical cell, for example) and ensures that a high signalto-noise ratio from the working electrode is collected. This is a useful advantage when using small samples, such as MCEs, which typically contain sub-milligrams of active material.

The beamline sample stage allowed translations in three dimensions with a $10 \mu \mathrm{m}$ resolution. This ensured that the cell could be aligned in each direction by remotely moving the stage; the MCE was aligned in the $X$ and $Y$ directions using an $X$-ray imaging detector (which was removed during EDXD measurements). Fig. 2 shows $\mathrm{X}$-ray images of a $\mathrm{UO}_{2}$-filled MCE in the electrochemical cell. $X-Y$ alignment was achieved by moving the $\mathrm{X}$-ray slits over a $\mathrm{UO}_{2}$-filled hole using live images. This alignment procedure had to be repeated for each new sample that was inserted into the cell. The slits created a $0.3 \mathrm{~mm} \times 0.3 \mathrm{~mm}$ square X-ray beam which helped to increase 

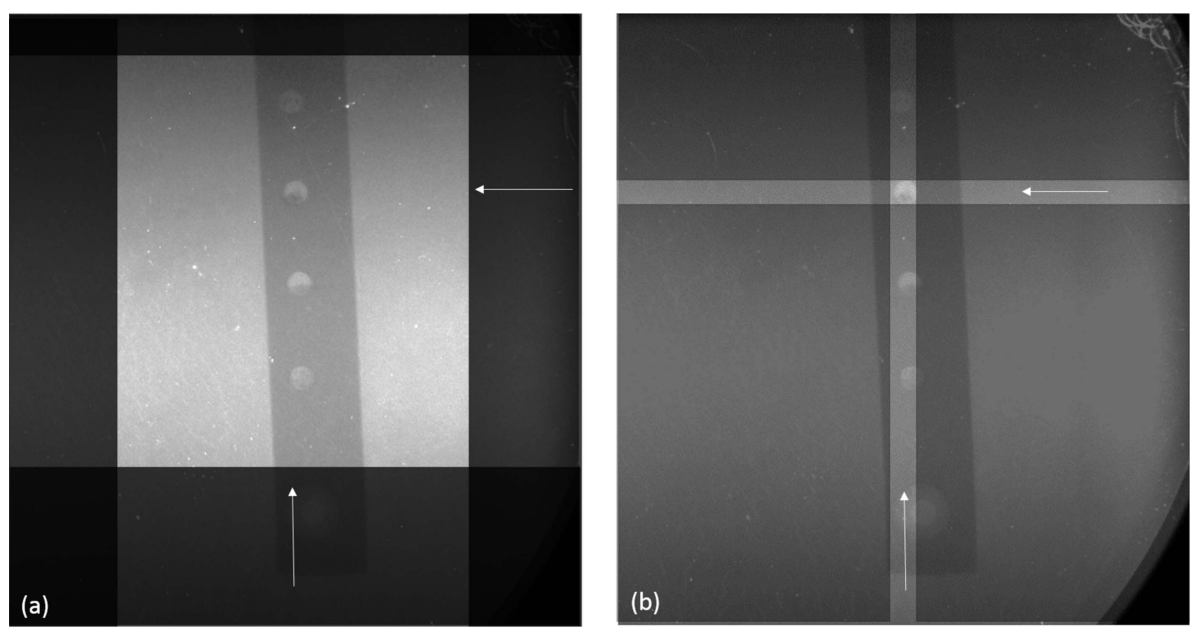

Figure 2

$\mathrm{X}$-ray radiographs of the MCE in the well of the electrochemical cell showing $X-Y$ alignment. (a) The MCE with the slits open and (b) complete alignment of the $\mathrm{UO}_{2}$-filled hole. was performed for $2 \mathrm{~h}$ to remove any electro-active species in the salt. For this, a molybdenum rod (>99\%, Alfa Aesar) working electrode was held $200 \mathrm{mV}$ more positive to the $\mathrm{Li}$ deposition potential, until the current fell to a value $<10 \mathrm{~mA}$. After preelectrolysis, the molybdenum rod was manually removed from the salt, after which a fresh $\mathrm{UO}_{2}$-filled $\mathrm{MCE}$ was inserted into the electrochemical cell. The cell was aligned to the centre of the incident $\mathrm{X}$-ray beam in the $X$ and $Y$ axes using the translation sample stage and imaged using X-ray radiography. The cell was then aligned in the $Z$-axis by optimizing the peak intensities of $\mathrm{UO}_{2}$ at different positions along the incident $\mathrm{X}$-ray beam using the EDXD detector. the signal-to-noise ratio of $\mathrm{UO}_{2}$. For alignment in the $Z$ direction, it was necessary to move the MCE into the middle of the lozenge-shaped gauge volume. This was achieved by scanning the stage's position along the X-ray beam direction ( $Z$-direction) to optimize the signal-to-noise ratio of $\mathrm{UO}_{2}$ observed by the EDXD detector.

During experimentation, a $0.3 \mathrm{~mm} \times 0.3 \mathrm{~mm}$ polychromatic $\mathrm{X}$-ray beam of energies ranging from 45 to $150 \mathrm{keV}$ irradiated a single $\mathrm{UO}_{2}$-filled cavity on the $\mathrm{MCE}$ working electrode, inside the electrochemical cell. EDXD data were collected with a cryogenically cooled 23-element, high-purity, germanium detector (Canberra Industries). The 23 detector elements are spaced every $8.18^{\circ}$, allowing azimuthal angles from $0^{\circ}$ to $180^{\circ}$ to be covered. The EDXD data collection was synchronized with the electrochemical measurements using an exposure time of $10 \mathrm{~s}$. The take-off angle of $4.5^{\circ}$ was defined by the collimating slits; all other X-rays which are diffracted at angles not equal to $4.5^{\circ}$ were not detected. The collected diffraction patterns over the 23 elements were then averaged to produce a powder-averaged diffraction pattern, improving the data quality. The resulting EDXD data are plotted as a function of the photon energy of the diffracted X-rays, in contrast to angular-dispersive $\mathrm{X}$-ray diffraction data that are obtained at a single wavelength and plotted as a function of the scattering angle, 2 $\theta$. All data were fitted using the Le Bail refinement. The Reitveld modelling approach was considered but was not used as it would have added extra complications that were not necessary for a relatively complex system studied here. Also, the likelihood of sample movement was relatively high (due to the volume change associated with reduction) which would have modified the absorption characteristics which need to be carefully considered (Rowles et al., 2012; Scarlett et al., 2009).

\section{Experimental}

During experimentation, the electrochemical cell was heated to $500^{\circ} \mathrm{C}$ and left to thermally stabilize for $1 \mathrm{~h}$. Pre-electrolysis
After alignment, continuous EDXD measurements were taken before, during and after exposing the $\mathrm{UO}_{2} \mathrm{MCE}$ to potentials more negative than the Li deposition potential of the LKE electrolyte. Due to this potential, $\mathrm{Li}^{+}$would be reduced to $\mathrm{Li}$ metal via equation (1) and plate onto the working electrode. The $\mathrm{Li}$ metal then chemically reduces $\mathrm{UO}_{2}$ via equation (2),

$$
\begin{gathered}
\mathrm{Li}^{+}+\mathrm{e}^{-} \rightarrow \mathrm{Li} \\
\mathrm{UO}_{2}+4 \mathrm{Li} \rightarrow \mathrm{U}+2 \mathrm{Li}_{2} \mathrm{O}
\end{gathered}
$$

The peak intensities for $\mathrm{U}$ and $\mathrm{UO}_{2}$ were recorded every minute on each of the 23 EDXD detector elements and averaged to produce a single powder averaged diffraction pattern.

\section{Results and discussion}

Sample averaged powder diffraction patterns obtained from continuous EDXD measurements are presented in Fig. 3 before and after $\mathrm{Li}$ deposition onto the $\mathrm{UO}_{2}$ working electrode.

In Fig. 3( $a$ ), a prominent peak exists corresponding to the intensities of $\mathrm{UO}_{2}$ and Mo obtained by EDXD measurements on the $\mathrm{UO}_{2}$ working electrode. After Li deposition, the peak intensities of $\mathrm{UO}_{2}$ disappear and peaks characterizing $\mathrm{U}$ metal appear; Video S1 in the supporting information shows the transition from $\mathrm{UO}_{2}$ to $\mathrm{U}$ metal during the continuous EDXD measurements. From this, the point of Li deposition is easily observed as the peak intensities of $\mathrm{UO}_{2}$ all reduce whilst those for $\mathrm{U}$ metal appear. It is also possible to observe from Fig. 3 and Video S1 that the peak intensities for $\mathrm{UO}_{2}$ fall to unobservable levels, indicating full chemical reduction of $\mathrm{UO}_{2}$ to $\mathrm{U}$. A total of 5.7 $\mathrm{C}$ was passed during Li plating, which would result in a mass of $\sim 0.4 \mathrm{mg}$ of deposited Li. From equation (2), this amount of $\mathrm{Li}$ would allow for $0.1 \mathrm{mg}$ of $\mathrm{UO}_{2}$ to be reduced. The MCE electrodes hold approximately $0.04 \mathrm{mg}$ of $\mathrm{UO}_{2}$ powder (Brown et al., 2015) and results in an efficiency of 


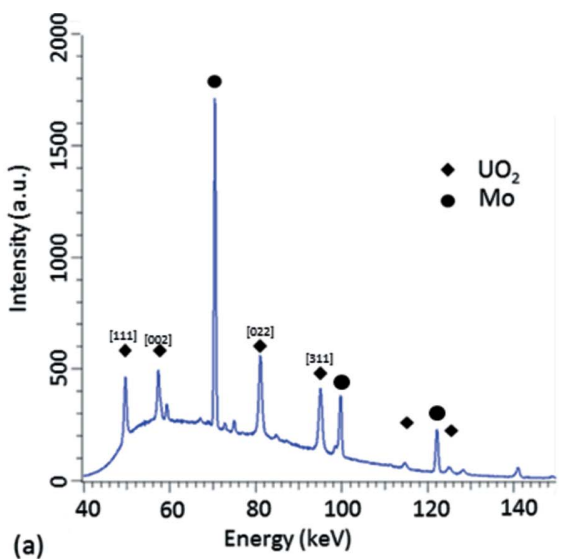

Figure 3

Sample single powder averaged diffraction patterns obtained $(a)$ before Li deposition and $(b)$ after $\mathrm{Li}$ deposition. Unmarked peaks are either minor peaks or $\mathrm{Mo} / \mathrm{Al}$ fluorescence peaks. The $h \mathrm{kl}$ values for selected peaks are shown in square brackets.

$40 \%$. This efficiency is likely to be heavily affected by the fact that Li metal exists in the liquid state under the conditions employed.

Moreover, Fig. 4 shows the change of peak intensity for the prominent peak crystal planes for both $\mathrm{UO}_{2}$ and $\mathrm{U}$ metal versus time. Peak intensities for the $\mathrm{U}$ phase start at zero, while peaks for $\mathrm{UO}_{2}$ are all observable. After $\sim 650 \mathrm{~s}$, the cell is subjected to potentials more negative than the decomposition potential of the LKE electrolyte for $10 \mathrm{~s}$. At this point, $\mathrm{Li}$ metal would be electrochemically plated onto the $\mathrm{UO}_{2}$-filled working electrode. After Li has been plated onto the electrode, the peak intensities for $U$ begin to increase as the peak intensities for $\mathrm{UO}_{2}$ begin to decrease. In addition, the peak intensities for each observable plane for $\mathrm{UO}_{2}$ are all seen to fall to a value of zero. This is indicative of the chemical reaction proceeding to completion. The intensity of the diffraction peaks of $U$ is seen to decrease slightly at $\sim 900 \mathrm{~s}$

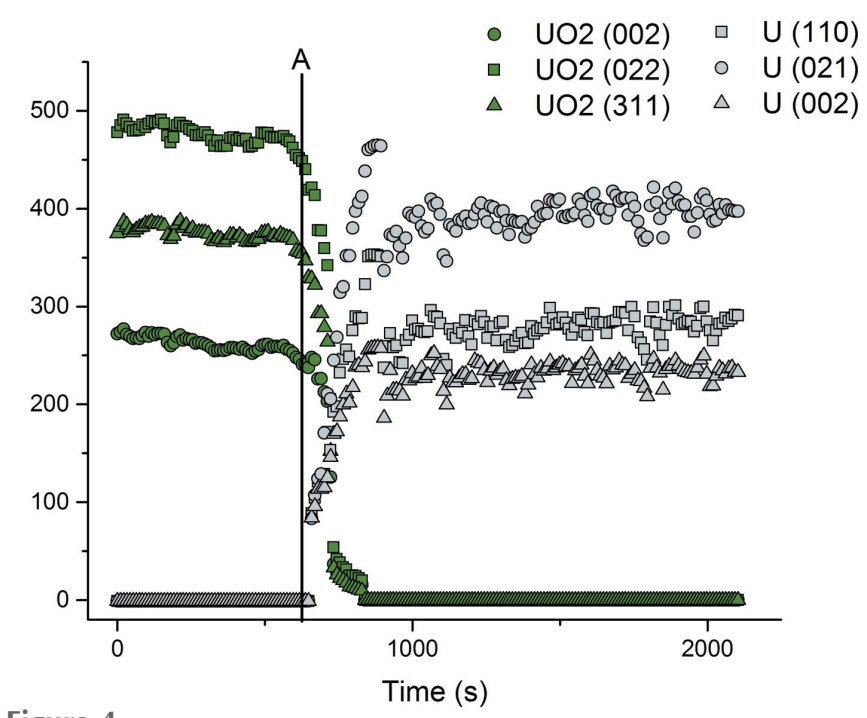

Figure 4

Peak intensities for different crystal planes of $\mathrm{UO}_{2}$ and $\mathrm{U}$ metal versus time during continuous EDXD measurements. The line denoted ' $\mathrm{A}$ ' depicts the point that $\mathrm{Li}$ deposition occurred, at $\sim 650 \mathrm{~s}$. and is most likely due to small amounts of powder falling out of the MCE due to the volume change associated with the reduction process (Brown et al., 2016). In the context of pyroprocessing, this oxide reduction process could potentially be performed inside the electrorefiner unit, negating the use of the direct oxide reduction unit. The use of the electrochemical cell described in this work enabled high signal-to-noise ratios to be attained, as shown in Fig. 3.

\section{Conclusions}

A novel electrochemical cell has been constructed in order to allow for in situ energy-dispersive $\mathrm{X}$-ray diffraction to follow the reduction of $\mathrm{UO}_{2}$ to $\mathrm{U}$ in molten lithium chloridepotassium chloride eutectic. Peak intensities for $\mathrm{UO}_{2}$ are all seen to reduce to unobservable levels simultaneously as peak intensities for $U$ metal increase, suggesting the reaction goes to completion, as expected. The electrochemical cell allowed for sub-milligram samples of powder to be studied in a hightemperature molten-salt environment due to its inherent design: the material of construction and the 'well' both substantially reduce X-ray attenuation, resulting in high signal-to-noise ratios. The use of sub-milligrams of powder allowed for low current responses and, thus, lower voltage drop due to ohmic losses (iR) to be studied, increasing the accuracy of electrochemical experimentation. The cell design is also expected to be applied to other molten-salt systems and to different geometries of electrodes, including pellet and thinfilm electrodes.

\section{Acknowledgements}

This work was carried out as part of the UK Engineering and Physical Sciences Research Council (EPSRC) funded REFINE consortium (http://www.refine.eng.ed.ac.uk/). We gratefully acknowledge this EPSRC financial support (EP/ J000531/1). We thank Diamond Light Source for access to beamline I12 (EE9690-1) that contributed to the results presented here. PRS thanks the Royal Academy of Engineering for financial support. We dedicate this publication to the memory of Professor Douglas Inman.

\section{References}

Alexander, D. T. L., Schwandt, C. \& Fray, D. J. (2006). Acta Mater. 54, 2933-2944.

Bhagat, R., Dye, D., Raghunathan, S. L., Talling, R. J., Inman, D., Jackson, B. K., Rao, K. K. \& Dashwood, R. J. (2010). Acta Mater. 58, 5057-5062.

Brown, L. D., Abdulaziz, R., Jervis, R., Bharath, V. J., Atwood, R. C., Reinhard, C., Connor, L. D., Simons, S. J. R., Inman, D., Brett, D. J. L. \& Shearing, P. R. (2015). J. Nucl. Mater. 464, 256-262. 
Brown, L. D., Abdulaziz, R., Simons, S., Inman, D., Brett, D. J. L. \& Shearing, P. R. (2013). J. Appl. Electrochem. 43, 1235-1241.

Brown, L. D., Abdulaziz, R., Tjaden, B., Inman, D., Brett, D. J. L. \& Shearing, P. R. (2016). J. Nucl. Mater. 480, 355-361.

Chen, G. Z., Fray, D. J. \& Farthing, T. W. (2000). Nature (London), 407, 361-364.

Drakopoulos, M., Connolley, T., Reinhard, C., Atwood, R., Magdysyuk, O., Vo, N., Hart, M., Connor, L., Humphreys, B., Howell, G., Davies, S., Hill, T., Wilkin, G., Pedersen, U., Foster, A., De Maio, N., Basham, M., Yuan, F. \& Wanelik, K. (2015). J. Synchrotron Rad. 22, 828-838.

Dring, K., Dashwood, R. \& Inman, D. (2005). J. Electrochem. Soc. 152, E104-E113.

Hu, D., Stevenson, A. \& Chen, G. Z. (2014). ECS Trans. 64, 585-592.

Hur, J.-M., Seo, C.-S., Hong, S.-S., Kang, D.-S. \& Park, S.-W. (2003). React. Kinet. Catal. Lett. 80, 217-222.

Jackson, B., Dye, D., Inman, D., Bhagat, R., Talling, R., Raghunathan, S., Jackson, M. \& Dashwood, R. (2010). J. Electrochem. Soc. 157, E57-E63.

Jeong, S. M., Shin, H.-S., Hong, S.-S., Hur, J.-M., Do, J. B. \& Lee, H. S. (2010). Electrochim. Acta, 55, 1749-1755.

Kämpfe, B., Luczak, F. \& Michel, B. (2005). Part. Part. Syst. Charact. 22, 391-396.

Kurata, M., Inoue, T., Serp, J., Ougier, M. \& Glatz, J.-P. (2004). J. Nucl. Mater. 328, 97-102.
Laidler, J. J. (1993). Presented at GLOBAL'93 - International Conference on Future Nuclear Systems: Emerging Fuel Cycles and Waste Disposal Options, 12-17 September 1993, Seattle, WA, USA. Laidler, J. J., Battles, J. E., Miller, W. E., Ackerman, J. P. \& Carls, E. L. (1997). Prog. Nucl. Energy, 31, 131-140.

Pierce, R. D., Johnson, T. R., McPheeters, C. C. \& Laidler, J. J. (1993). JOM, 45, 40-44.

Qiu, G., Ma, M., Wang, D., Jin, X., Hu, X. \& Chen, G. Z. (2005). J. Electrochem. Soc. 152, E328.

Rao, K., Brett, D., Inman, D. \& Dashwood, R. J. (2007). Proceedings of the 11th World Conference on Titanium (Ti-2007), 3-7 June 2007, Kyoto, Japan. The Japanese Institute of Metals.

Rowles, M. R. (2011). J. Synchrotron Rad. 18, 938-941.

Rowles, M. R., Styles, M. J., Madsen, I. C., Scarlett, N. V. Y., McGregor, K., Riley, D. P., Snook, G. A., Urban, A. J., Connolley, T. \& Reinhard, C. (2012). J. Appl. Cryst. 45, 28-37.

Scarlett, N. V. Y., Madsen, I. C., Evans, J. S. O., Coelho, A. A., McGregor, K., Rowles, M., Lanyon, M. R. \& Urban, A. J. (2009). J. Appl. Cryst. 42, 502-512.

Schwandt, C. \& Fray, D. J. (2005). Electrochim. Acta, 51, 66-76.

Seo, C. S., Park, S. B., Park, B. H., Jung, K. J., Park, S. W. \& Kim, S. H. (2006). J. Nucl. Sci. Technol. 43, 587-595.

Styles, M. J., Rowles, M. R., Madsen, I. C., McGregor, K., Urban, A. J., Snook, G. A., Scarlett, N. V. Y. \& Riley, D. P. (2012). J. Synchrotron Rad. 19, 39-47. 